This item was submitted to Loughborough's Research Repository by the author.

Items in Figshare are protected by copyright, with all rights reserved, unless otherwise indicated.

\title{
Understanding individual experiences of cyberbullying encountered through work
}

PLEASE CITE THE PUBLISHED VERSION

http://pracademics.com/index.php/ijotb

\section{PUBLISHER}

(C) 2014 PrAcademics Press

\section{VERSION}

AM (Accepted Manuscript)

\section{PUBLISHER STATEMENT}

This work is made available according to the conditions of the Creative Commons Attribution-NonCommercialNoDerivatives 4.0 International (CC BY-NC-ND 4.0) licence. Full details of this licence are available at: https://creativecommons.org/licenses/by-nc-nd/4.0/

\section{LICENCE}

CC BY-NC-ND 4.0

\section{REPOSITORY RECORD}

Heatherington, Wayne, and lain J. Coyne. 2019. "Understanding Individual Experiences of Cyberbullying Encountered Through Work”. figshare. https://hdl.handle.net/2134/22449. 
In Press. International Journal of Organization Theory and Behavior

\title{
UNDERSTANDING INDIVIDUAL EXPERIENCES OF CYBERBULLYING ENCOUNTERED THROUGH WORK
}

\author{
Wayne Heatherington and Iain Coyne
}

Wayne Heatherington (MSc) is Talent Assessment and Selection Manager at the Co-Operative Group, but undertook this research during his MSc in Work and Organisational Psychology at the University of Nottingham.

Iain Coyne $(\mathrm{PhD})$ is Associate Professor of Occupational Psychology Institute of Work, Health and Organisations, University of Nottingham. His research interests are within workplace counterproductive behaviour with a focus on workplace bullying and cyberbullying. 


\begin{abstract}
Little research has explored individual experiences of cyberbullying in working contexts. To start bridging the gap in our current understanding, we used Interpretative Phenomenological Analysis (IPA) to explore individuals' shared experiences of cyberbullying encountered through work. In-depth interviews, conducted with five cyberbullied workers from the pharmaceutical, charity and university sectors, resulted in five superordinate themes: attributions of causality; crossing of boundaries; influence of communication media richness on relationship development; influence of communication explicitness and openness; and strategies for coping. Overall, some similarities emerged between cyberbullying experiences and traditional bullying research, yet the complexities associated with managing relationships, both virtually and physically, were central to individuals' subjective experiences. Practical implications in developing effective leadership and business policies to support virtual groups and manage behaviours are discussed.
\end{abstract}




\section{INTRODUCTION}

Sophisticated media for collaboration are increasingly being adopted by business to support virtual teamwork as well as asynchronous and distributed working (McAfee, 2009; Tapscott and Cook, 2008). However, there are also potential downsides to virtual working, including increased conflict that can be both difficult to isolate and manage (Hinds and Bailey, 2003; Mannix, et al., 2002). Organisations need to consider how to manage the potentially conflicting aims of developing organisational social capital and discouraging inappropriate use of technology (Li and Bernoff, 2008; Lieber, 2010).

Advances in communication technologies have been associated with the emergence of cyberbullying (Kowalski, et al,. 2008) which is defined as: "an aggressive intentional act carried out by a group or individual, using electronic forms of contact, repeatedly and over time against a victim who cannot easily defend him or herself" (Smith, et al., 2008: 376). To date, most research has centred on cyberbullying in children and young people (see Smith, et al., 2008). However, while it is well established that face-to-face bullying is problematic in the workplace (Einarsen, et al., 2010), the investigation of cyberbullying associated with individuals' working lives has received little attention. In addition, there is an ongoing debate on whether cyberbullying should be considered simply as bullying conducted in cyberspace (Campbell, 2005; Kowalski, et al., 2008), or whether such experiences are qualitatively different from experiences of face-to-face bullying (Dooley, et al., 2009; Slonje and Smith, 2008).

Given the increasing use of technology at work, the paucity of workplace cyberbullying research and the continued debate on the link between cyberbullying and face-to-face bullying; the current study adopts a qualitative perspective to provide some initial indication of individuals' personal experiences of cyberbullying and whether such experiences are qualitatively different to those seen in face-to-face working contexts. The research will provide an in-depth understanding of how individuals experience cyberbullying at work and will help researchers and practitioners develop an initial understanding of this phenomenon, to aid future research and practice in this area.

\section{Face-to-Face Workplace Bullying}

Since the late 1980s research on face-to-face workplace bullying has increased to the extent that we now have a global perspective on this repetitive and enduring workplace behaviour (Coyne, 2011). Large scale surveys have suggested victim rates of 3.5\% (Leymann, 1996), 10.6\% (Hoel et al., 2001) and 28\% (Lutgen-Sandvik et al., 2007) and evidence indicates bullying impacts negatively on the general health and well being of victims (e.g. Bowling and Beehr, 2006). Further, victims tend to adopt avoidance or resignation approaches to coping with being bullied (Ólafsson and Jóhannsdóttir, 2004) which has subsequent effects for organisations in terms of absenteeism (Agervold and Mikkelsen, 2004), turnover intention (Djurkovic et al., 2004) and legal, replacement and training costs.

Identification of antecedents of workplace bullying has tended to be dominated by organisational explanations. Summing up the extant research, Hoel and Salin (2003) posit that: the changing nature of work; the organisation of work (e.g. stressful work environments, role ambiguity); organisational culture conducive to bullying; and poor leadership promote workplace bullying. Such factors provide the enabling, motivating and precipitating processes for bullying to emerge (Salin, 2003).

By contrast, other researchers have argued that victim disposition may predispose an individual to be targeted because such individuals are vulnerable targets (submissive victim) or via provocation due to conflict escalation or envy perceptions (provocative victim) (Coyne et al., 2000). Similarly, perpetrator disposition in relation to tyrannical (Ashforth, 1994) or aggressive behaviour (Seigne et al., 2007) may predispose an individual to act in an aggressive manner. Recognising the complex nature to workplace bullying, recent developments in theoretical models have professed more of an interactional component between individual and organisational factors (Bowling and Beehr, 2006; Einarsen et al., 2010).

\section{Cyberbullying at Work}

Cyberbullying can take many forms from sending inappropriate, threatening and/or harassing emails/text messages, through setting up hate websites, to disclosing personal details of another person on the internet. Although not a new phenomenon per se, the increasing misuse of technological means of communication by children and young adults has resulted in more attention being paid to this form of negative interpersonal behavior (Rivers et al., 2011). Systematic research into workplace cyberbullying is currently in its infancy, with most of our present understanding emerging from children and youth contexts. Surveys of youths have shown cyber-victim rates of 12\% (Slonje and Smith, 2008); 25\% (Li, 2006) and 49\% (Raskauskas and Stoltz, 2007). 
However, akin to workplace bullying research, rates vary due to the different criteria and different media used to identify victims. Evidence also points to a negative impact on young peoples' psychological well-being with victims experiencing sadness, hurt, anger, frustration (Beran and Li, 2005; Patchin and Hinduja, 2006), and depression (Ybarra, 2004).

Some researchers have argued that the cyber-environment has unique elements which may explain the emergence of cyberbullying and make the impact of cyberbullying worse than for face-to-face bullying (e.g. Campbell, 2005; Dooley, et al., 2009; Mishna, et al., 2009; Patchin and Hinduja, 2006). Specifically:

- the anonymity afforded by the technology allows the bully to become 'invisible' and may result in the bully being less conscious of the impact of his or her actions on the target;

- the access to, use of, and openness of the technology means the individual can become a perpetual target beyond the school or working context;

- ineffective formal and informal control mechanisms and supervision online reduces the risk of being caught cyberbullying;

- a victims lack of power, rather than a perpetrators possession of power explains the power differential in cyberbullying;

- abusive messages on the Internet may only be posted by an individual once, yet that message may be viewed by a large number of people or posted on by other people a number of times.

However, the nature and prevalence of cyberbullying in the workplace and the significance of the communication device and medium remains unclear. Where systematic research has been conducted, workplace cyberbullying rates of 9\% (Baruch, 2005) and 10.7\% (Privitera and Campbell, 2009) have been reported. Yet, it should be acknowledged here that (similar to the initial research in workplace bullying) different methodologies are used to identify cyberbullying rates. Baruch only focused on email bullying, whereas Privitera and Campbell, used an adapted version of the Negative Acts Questionnaire and included bullying via email, SMS and phones.

Rivers et al., (2011) argue researchers in computer-mediated communication (CMC) explored behaviours of 'flaming', 'flooding', 'kicking', and 'spamming' well before we adopted the term 'cyberbullying'. Although these concepts are not cyberbullying as defined currently in the literature, consultation of this literature may provide some initial indications as to the development of negative online communication which may help to enhance our understanding of workplace cyberbullying. Within CMC, reduced social cues, group norms and online subcultures all present possible, and potentially interacting explanations for aggressive communication online (Lea, et al., 1992). The reduced social cues approach argues that aggressive online behaviour is a function of the nature of the communication medium itself. The social cues people use to form impressions of others in offline communication are predominantly non-verbal and these are greatly reduced in electronic communication media (Sproull and Kiesler, 1986). Wallace (2001) refers to this as the 'chilly internet' effect (p.15). By removing social cues internet communication is more 'free' and behaviour is less inhibited (Kiesler $e t$ al., 1984; Joinson, 2003). Suler (2004) suggests six factors contribute to this 'disinhibition' effect: Dissociative anonymity (separation of actions from identity); Invisibility (not seeing or hearing others creates a sense of invisibility); Asynchronicity (the lack of real time communication); Solipsistic introjection (absence of facial cues can result in an individual creating their own character for the person they are communicating with); Dissociative imagination (online persona is nothing to do with the real world); Minimisation of status and authority (absence of authority cues makes a person more willing to speak out). Siegel et al. (1986) argue that submergence within the technology, the lack of social feedback and the potential for anonymity seen in computer-mediated communication creates a deindividuation effect which reduces concern about own behaviour and causes actions that are unrestrained and disinhibited. However, Postmes et al., (1998) metaanalysis exhibited no support for increased anti-normative behaviour due to deindividuation.

On the other hand, aggressive online behaviour may be a result of social norms that define appropriate online behaviour, rather than absence of social cues per se. Interactions are guided by these norms and a computing subculture emerges (Ybarra, 2004). Poole and DeSanctis (1990) argue that group norms are determined by the technology itself and how the group uses the technology. However, Postmes et al., (1998) showed that only deindividuated individuals tended to comply with online social norms. Anonymity moves an individual's awareness away from personal identity to social identity (part of the group), resulting in them conforming to the group's norms and behaving in a manner accepted by the group (Reicher, 1982). In a cyberbullying context, a deindividuated individual is more likely to conform to a group norm and if this norm is to be abusive and 
aggressive online, the individual is likely to behave in a similar manner. These ideas have been formulated into the Social Identity model of Deindividuation Effects (SIDE) for CMC (Reicher et al., 1995).

In conclusion, little is currently known about individuals' experiences of cyberbullying within work contexts. Qualitative inquiry provides a potential mechanism for discovering dimensions of cyberbullying that may be less visible in quantitative studies and such an approach has provided insight into cyberbullying in a school context (Mishna, Saini, \& Solomon, 2009; Spears, Slee, Owens, \& Johnson, 2009). This exploratory study aims to enhance our understanding of this emerging psychosocial phenomenon by considering two research questions:

\section{What are individuals' specific and shared experiences of cyberbullying encountered through work? \\ To what extent are experiences similar or different to face-to-face bullying?}

\section{METHOD}

\section{Participants}

Five participants (one female, four males; age range: 40-48) were purposively selected from organisations across the private (pharmaceuticals), public (university) and voluntary (charity) sectors through an informal networking process (Table 1). This process involved initially approaching contacts within the first author's LinkedIn network and then posting a wider invitation to a LinkedIn site on bullying.

Table 1: Interview participants

\begin{tabular}{lllll}
\hline Victim & Age & Job & Perpetrator & Sector \\
\hline Alison & 44 & Library Manager & US-based Line Manager & Pharmaceuticals \\
John & 40 & IT Consultant & US-based Senior Director & Pharmaceuticals \\
Tony & 40 & IT Consultant & US-based Senior Director & Pharmaceuticals \\
Mark & 48 & Executive Director & UK-based Board Members & Charity \\
Andrew & 43 & Postdoctoral Scientist & UK-based Line Manager & University \\
\hline
\end{tabular}

To capture individual experiences of cyberbullying, we used Interpretative Phenomenological Analysis (IPA) (Smith and Osborn, 2003). IPA was developed to explore how individuals 'make sense' of their experience and is concerned with describing individual lived experiences. The aim is to develop a theoretical account that establishes its validity by resonating both with participants, in that it accords with their personal understanding of their experience, and to a wider audience, through a credible link with participants' accounts.

Due to the idiographic nature of IPA, sample sizes are usually small with four to six cases cited as a benchmark sample size (Smith and Osborn, 2003). Sample size was also limited by the sensitive and emerging nature of the subject under study which, it is assumed, may have been associated with a reticence to participate and individuals' uncertainty regarding their appropriateness as research participants. The IPA sampling strategy endeavours to identify germane and varied examples within an otherwise homogeneous group in order to encompass diverse and rich perspectives on the same phenomena that are amenable to theoretical analysis. Sample inclusion criteria were determined by the research question, namely individuals who perceived that they had experienced cyberbullying during the course of their work. Participation was restricted to individuals based in the UK, which enabled face-to-face interviews to be conducted.

\section{Procedure}

All participants consented to confidential semi-structured interviews, in locations of their choosing, of up to 1 hour duration. In all cases, participants consented that interviews be recorded and that illustrative quotes could be used in any publications arising from the interviews. Participants were also informed that all data would be both anonymous and confidential and that following transcription, recordings would be deleted. Names have been changed to protect confidentiality.

An interview schedule (available from the author on request) was developed covering experiences of, the impact of and causes of the cyberbullying. However as experts of their own experience (Smith and Osborn, 2003), participants were encouraged to cover anything they felt appropriate to their experience of cyberbullying through work, with minimal direction from the researcher. This was achieved through a combination of 
empathic review (e.g. paraphrasing), interpretative review (e.g. checking understanding) and gentle opening probes (e.g. 'Can you tell me more about that?') designed to build rapport, develop discussion and elicit a deeper level of descriptive and emotional content.

Following an explanation of the purpose of the study and reaffirming consent, each interview opened with the following question: 'Can you tell me about your experience of cyberbullying at work?' No definition of cyberbullying at work was provided as the interest was in participants' descriptions and interpretations of experiences they regarded as being associated with cyberbullying at work.

\section{Analysis}

Analysis was conducted on verbatim transcripts created from interviews with all five participants following the approach suggested by Smith et al. (2009). Analysis began with a close interpretative reading of the first case, which was selected based on the perceived richness of content, with initial responses annotated in the right hand margin. These annotations were translated into emergent themes at one higher level of abstraction and recorded in the left hand margin. These emergent themes were then clustered into sets of superordinate and subordinate themes. This process was repeated for all cases. As detailed by Smith et al, (2009) a second researcher undertook a mini independent audit by examining the transcripts and coding to ensure themes were grounded and well represented in the participants' accounts. Then, through an iterative process of analytic induction, patterns were established across cases and a master table of superordinate and subordinate themes was constructed, supported with representative quotations. This approach enables adherence to idiographic principles whilst also providing a tentative bridge to nomethetic principles and the opportunity to explore potentially universal themes (Smith et al 1995).

\section{RESULTS}

Five superordinate themes emerged as key elements of how individuals' experienced cyberbullying encountered through work: attributions of causality; crossing of boundaries; influence of communication media richness on relationship development; influence of communication explicitness and openness; and strategies for coping. Table 2 provides an overview of superordinate and subordinate themes for each participant. An illustrative quote is provided in the text and a further quote provided for each subtheme in Appendix 1. Potentially identifying information has been removed from quotations and replaced in rounded brackets with a more generic term.

\section{Attributions of Causality}

Here, attributions of causality refer to factors participants perceived as contributing to their experience of cyberbullying at work. Such attributions can be divided into three distinct subthemes: attribution to situational and organisational factors; attributions to self and attributions to perpetrator(s).

Attributions to Situational and Organisational Factors

All participants referred to situational and organisational factors that they perceived served as antecedents to their experience of cyberbullying. These included the influence of organisational structures, organisational politics and organisational change. As Alison states: "they reorganised (name of group) and we started to report into a lady based in [X] ..., so as you can imagine the time difference was something that was a bit of an issue to start with". Individual working patterns were also referred to as a contributory factor. Mark put it like this: "they being voluntary people, erm, would come up with an idea and have a thought, and they would send me an email, and it might be at 10 o'clock at night, or 11 o'clock at night, or sometimes they'd wake up in the middle of the night and have a thought, they'd send me an email. And knowing that I was coming into work at half past seven, this idea that emails are answered immediately...."

Attributions to Self

Participants referred to aspects of their own personality as contributing factors. Mark indicated "there was a vulnerability in me" also stating " $m y$ family say that I don't say sorry often enough, or that I don't acknowledge my part in things, and that I maybe therefore bring it on."

\section{Attributions to the Perpetrator}

Four participants referred the personality of the perpetrator as a driving force behind the cyberbullying. Tony describes "a very schizophrenic individual", and Mark "a person who it turned out, erm, did have anger management issues." 
Table 2: Super- and subordinate themes for participants (identifying recurrent themes)

\begin{tabular}{|c|c|c|c|c|c|}
\hline \multirow{2}{*}{$\begin{array}{l}\text { Superordinate Themes } \\
\text { Subordinate Themes }\end{array}$} & \multicolumn{5}{|c|}{ Participants } \\
\hline & Alison & John & Tony & Mark & Andrew \\
\hline \multicolumn{6}{|l|}{ Attributions of causality } \\
\hline Attributions to situational \& organisational factors & $\checkmark$ & $\checkmark$ & $\checkmark$ & $\checkmark$ & $\checkmark$ \\
\hline Attributions to self & $\checkmark$ & & & $\checkmark$ & $\checkmark$ \\
\hline Attributions to perpetrators & $\checkmark$ & $\checkmark$ & $\checkmark$ & & $\checkmark$ \\
\hline \multicolumn{6}{|l|}{ Crossing of Boundaries } \\
\hline Boundary between work and personal life & $\checkmark$ & & & $\checkmark$ & \\
\hline $\begin{array}{l}\text { Boundaries between established and emerging } \\
\text { organisational structures }\end{array}$ & $\checkmark$ & $\checkmark$ & $\checkmark$ & $\checkmark$ & \\
\hline \multicolumn{6}{|l|}{$\begin{array}{l}\text { Influence of Communication Richness on Relationship } \\
\text { Development }\end{array}$} \\
\hline $\begin{array}{l}\text { Role of Empathy, Socialisation and Disclosure to } \\
\text { Trust Formation }\end{array}$ & $\checkmark$ & $\checkmark$ & & $\checkmark$ & \\
\hline Significance of Verbal and Non-Verbal Cues & $\checkmark$ & & & $\checkmark$ & $\checkmark$ \\
\hline \multicolumn{6}{|l|}{ Influence of Communication Explicitness and Openness } \\
\hline $\begin{array}{l}\text { Influence on perpetrator's bullying behaviours } \\
\text { (indirect versus indirect) and impact on victim }\end{array}$ & $\checkmark$ & $\checkmark$ & $\checkmark$ & $\checkmark$ & $\checkmark$ \\
\hline Influence on group dynamics & $\checkmark$ & $\checkmark$ & $\checkmark$ & & \\
\hline \multicolumn{6}{|l|}{ Strategies for Coping } \\
\hline Avoiding & $\checkmark$ & $\checkmark$ & $\checkmark$ & $\checkmark$ & \\
\hline Confronting & & $\checkmark$ & $\checkmark$ & $\checkmark$ & $\checkmark$ \\
\hline Controlling & & $\checkmark$ & $\checkmark$ & & $\checkmark$ \\
\hline Seeking Revenge & & & $\checkmark$ & & \\
\hline
\end{tabular}

\section{Crossing of Boundaries}

Unlike the traditional perspective on boundaries being vertical, horizontal, external, geographical and temporal (Ashkenas et al. 1993); the boundary between the physical and virtual worlds in which individual inhabit emerged as important to participants' experiences of cyberbullying. Two subordinate themes were presented: the boundary between work and personal life; and the boundaries between established and emerging organisational structures and culture.

\section{Boundary Between Work and Personal Life}

Two participants described how the use of communication technologies has reduced the boundary between work and personal life and how perceived boundary breaches contributed to their experiences. Alison describes how deeply troubling she found the ambiguity that existed between work life and personal life and the impact that her manager crossing this porous boundary had on her. Mark describes being distressed and angry when board members shared and repeatedly contacted him via his personal e-mail account. Alison went on to describe the crossing of the boundary as:

"Intrusive, because I was sitting in my spare room and I was working from home but, I suddenly thought, yunno I've got you in work, in the 'workplace' workplace, but I'm working still here now, but I'm in my home and you're doing this. And I'm supposed to feel safe here." 
Both Tony and John, who work for the same pharmaceutical company, describe situations where conflict emerged out of the tension between the formal, vertical, hierarchical organisational structure and an informal, horizontal, organic structure that was emerging. These structures supported different organisational cultural imperatives. Managerial control supported traditionally through a hierarchical structure, and collaboration facilitated through group communication technologies and social media, such as blogs and virtual collaboration environments, which enabled horizontally distributed social capital and expertise networks to be established. Consequences of this tension were acts of direct and indirect cyberbullying and bullying. Tony describes receiving this message:

"one of my colleagues who I was collaborating with suddenly emailed me, erm, no sorry im'ed [instant messaged] me in a very threatening way, telling me that I had to retract something that I'd published onto the web, erm, and it was done in a - 'you will do this, don't even ask, I will then escalate this if you don't do this to, yunno, senior management, within the organisation'. And I.., there was no explanation or context as to why this was, it just felt out of the blue, it felt like: 'thou shalt do this. I'm very important, you're not, I'm going to cause you an awful lot of pain and trouble if you don't do exactly what I am telling you'."

\section{Influence of Communication Media Richness on Relationship Development}

Media richness refers to the capacity for a communication medium to reproduce information (e.g. verbal, auditory, visual, and tactile) (Daft and Lengel, 1986). Two potentially inter-related subordinate themes emerged in participants' descriptions of frustrations they experienced in trying to establish and develop relationships with the perpetrators of cyberbullying. Firstly, Alison discusses the absence of displays of empathy, social talk and disclosure in communications with her manager as an impediment to the development of a trusting relationship. Secondly, three participants describe difficulties associated with the lack of non-verbal information and quality of verbal information communicated electronically.

Role of Empathy, Socialisation and Disclosure to Trust Formation.

During the formative stages of Alison's relationship with her manager, all communication was electronicallymediated (e-mails, telephone calls and group teleconferences). Alison attributed the early signs of problems in her relationship with her manager to her need for an empathic relationship. 'I'm sort of a warming person', and her manager's failure to demonstrate it as creating 'a clash at the beginning.' Alison attributes this to personality characteristics, however, there is some indication that the richness of communication that can be carried through electronic communication media may have influenced the development of her first impressions of her manager when Alison describes meeting her manager face-to-face for the first time:

"when we had that face-to-face and I opened up to her, I did, as I said to you, I did see a little bit of a softer side, but a lot of water had gone under the bridge at that point and I feel that that probably didn't help."

\section{Significance of Verbal and Non-verbal Cues}

Some participants suggested that the quality of information communicated via particular communication channels influenced their perceptions of behaviour and the intentions behind it, specifically, whether they considered the behaviour and underlying intent to be aggressive.' Mark describes problems with e-mail communication: "you can make a request of somebody in person that as an email becomes a demand." Such comments suggest that information communicated electronically is experienced differently to that which can be communicated face-to-face, as well as highlighting the significance of both verbal and non-verbal communication to sense-making. When asked about the form of communication, Alison believed that face-toface communication would have completely changed the trajectory of her relationship with her manager and her experience of being cyberbullied. Andrew suggests that the form of communication had importance in determining when, and if, his experiences amounted to cyberbullying. Mark reported that the perpetrator appears to recognise the leanness of electronically-communicated information and seeks to compensate for it: "the second reminder email came in caps and then in brackets afterwards he said: 'I'm shouting', closed brackets".

\section{Influence of Communication Explicitness and Openness}

Communication explicitness refers to the degree of transparency contained in the information that is communicated. Openness is defined as the explicitness of what is communicated within a group context. 
Andrew suggests that because there is a readily available record with electronically-mediated communication this influences the explicitness of message through which the perpetrator chooses to (cyber)bully. A perpetrator may engage in more indirect and covert aggressive behaviours to increase ambiguity and minimise the risk of being detected. This suggests a complex dynamic in which the openness of available communication channels can influence perpetrators' decisions regarding when and where to display direct, or alternatively indirect, bullying behaviours. For example, John describes open forms of indirect cyberbullying, which he framed around a concept called FUD:

"FUD - fear, uncertainty and doubt - and it is just about sprinkling enough doubt and fear around a given topic to warn people off, and there was a lot of that going on, erm, and, so I started to find it a bit of an uphill struggle, even within my own team, because suddenly there was doubts...."

Some participants experienced the openness of the communication medium as being problematic on three levels. Firstly, it could be used to publically denigrate "to show me up in front of my direct reports." [Alison]. Secondly, to escalate conflict through public displays of direct aggression: "I will offer outside [fight] anybody that even tries to argue with me on this point, as John describes his perpetrator stating it in a widely distributed email. Thirdly, and perhaps of special significance to cyberbullying in social virtual environments, John suggests a double-bind for the victim:

"this was kind of the irony, this person was still available, still able to see what I was doing ... and I became aware that he was in the background starting to email people so he wasn't doing it in the open anymore..."

\section{Influence of Power on Intra-group and Inter-group Dynamics}

John and Tony describe a range of group responses to cyberbullying behaviours displayed in online collaborative environments. John describes cyberbullying emerging from a group vested with formal organisational power and the negative impacts these had on the virtual community he was working with:

"they became very fearful about actually posting anything because they knew that these guys were going to come in and rip it to bits, yunno, and start just spreading scorn, and, yunno, and doubt and what have you. So what happened, and it was fairly quickly actually, er, we started off with a fairly healthy, vibrant online community to start with, erm, and it just died."

In contrast, Tony suggests such experiences played a role in reinforcing group identity and that these tacitly espoused shared values helped the development of social power:

"it became a kind of glue, or it became one of the kind of things that banded people together, who were operating and trying to explore these new ideas and things, because it enabled us to define, if you like, who was in and who was out, or, who is the enemy and who is the friends, in a very crude sense."

\section{Strategies for Coping}

Participants describe employing a range of coping strategies which can be categorised into four subordinate themes: avoiding, confronting, controlling and seeking revenge.

Avoiding

Alison describes an incident of being off sick and not being physically co-located with her manager allowed her to maintain some avoidance coping strategies. John describes a process of 'going through the motions': "I very much feigned having interactions, and I still do have interactions with this individual, is that..., I'm wary about what I'm saying to them, I'm not as open and sharing with them.". Whereas Mark details using avoidance to cope with situations he perceives he could have otherwise dealt with had he been physically co-located with the perpetrators.

\section{Confronting}

In some situations confronting was used a coping strategy: "Erm, I caught him out one time, got included in on a thread and saw some of the stuff and replied and kind of called him on it essentially, and said, yunno, 'this is not right'." [John] However, confronting the issue can be a high risk strategy, as Mark found out when confronting his employers about work communications he received while on holiday (see Appendix 1).

\section{Controlling}


Tony refers to carefully choosing the medium in which to communicate with the perpetrator in order to maintain control and three participants referred to keeping records to maintain control. As this comment also from Tony, illustrates:

"I'm wary about what I'm saying to them, I'm not as open and sharing with them, and I keep a lot more records of all the conversations I have with them. So if things are, a bit, yunno, not quite perfect, I'll keep an IM conversation thread, with them and those sorts of things."

\section{Seeking Revenge}

One participant, Tony, described using revenge in response to being cyberbullied and that the online virtual environment, in which he had strong social affiliations, provided him with the social power to do it (see Appendix 1).

\section{DISCUSSION}

The current research provides insight into how individuals conceptualise their experience of cyberbullying. Five major themes captured individuals' shared experiences of cyberbullying encountered through work: attributions of causality; crossing of boundaries; influence of communication media richness on relationship development; influence of communication explicitness and openness; and strategies for coping. Much of the research currently in cyberbullying is atheoretical. Therefore, we consider our findings in relation to existing research in traditional/cyber bullying and electronic communication and structure the discussion to consider the extent that experiences of cyberbullying parallels those seen in face-to-face bullying contexts.

\section{Similarities with research seen in face-to-face bullying}

\section{Attributions of Antecedents}

Participant attributions of causality to individual characteristics and organisational factors concords with research in face-to-face bullying. For example, attributions to self, the perpetrator and the organisation are central components of the face-to-face victim harassment model (Bowling and Beehr, 2006).

At the individual level, victims characterised themselves as personally vulnerable and referred to low assertiveness and poor conflict management skills. Theoretically, the notion of submissive victims seen in traditional bullying, where individuals are unable to defend themselves and hence become the target of a perpetrator's aggression (Coyne, 2011), may explain causal attributions to self in this sample. Perpetrators were seen as being emotionally unstable, aggressive, controlling and directive, which again links to research in traditional contexts (Ashforth, 1994; Seigne, et al. 2007). Zapf and Einarsen (2003) theorised that perpetrators' low emotional control and lack of empathy could explain their engagement in bullying. Potentially in cyber communication, given the remote nature, the perpetrator is less aware of the victim's reaction than in face-toface contexts which may lead to a reduction in empathy (Slonje and Smith, 2008) or an increase in the intensity of the acts.

Similarly, organisational factors of change, working patterns and politics were attributed as contributing to experiences of cyberbullying. Once again, strong parallels are seen with antecedents of face-to-face bullying (Hoel and Salin, 2003). Akin to face-to-face bullying, the revised frustration-aggression hypothesis (Berkowitz, 1989) can be advanced as an explanatory framework. Frustrations in the work environment and the resulting ineffective coping mechanism adopted by the individual experiencing the frustration may result in bullying behaviour. Here, we do not have direct evidence for the coping mechanism of the perpetrator; yet stress and strains in the work environment were considered as antecedents by some participants.

However, the transition to more geographically and temporally distributed work appears to add greater structural complexity and ambiguity and suggests that the cyberbullying experience differs from face-to-face bullying. In the crossing of boundaries themes, a tension emerged between a desire to maintain managerial control and organise work (traditionally achieved through hierarchical structures) and the desire to innovate and gain efficiencies through horizontal, collaborative, social networks. Although, this could be framed within a traditional bullying conflict-escalation model (Zapf and Gross, 2001); tensions here emerge from the struggle and complexity in managing the boundaryless nature to the work which may be unique to a cyberbullying context.

\section{Power Relations}

Traditionally, an imbalance of power is seen as a defining criterion for face-to-face bullying, often on the basis of the perpetrator holding legitimate power (Hoel et al. 2001). This was reflected in John and Tony's accounts 
of cyberbullying, where each describes situations in which they perceived their respective perpetrators employed hierarchical positional power to reduce collaboration online. Indeed, in all cases perpetrators are in senior positions to the victims.

However, Tony describes how he perceived that inappropriate exertion of positional power acted both to reinforce group identification and inter-group conflict with the perpetrator and affiliates. This suggests a Social Identity Theory (Tajfel and Turner, 1986) explanation where those who share the tacitly espoused values of the online community created an in-group approach to support the rest of the community against the perceived outgroup (perpetrator and affiliates). As Tony described: “...it enabled us to define, if you like, who was in and who was out..." An interesting contrast emerges here. In John's case the formal power base of the perpetrator is perceived to be stronger than the power vested in the online community, whereas in Tony's case the in-group identity fostered social power that was perceived to be stronger than the formal power. The virtual environment could be easier or more open to the emergence of social power as compared to the face-to-face workplace environment.

In contrast to social network communication, power imbalances in dyadic interactions may be explained by the victim's feelings of powerlessness. The increased ambiguity in the boundary between work and personal lives generated feelings of intimidation, anger and anxiety, and created a sense that there was no getting away from the cyberbullying ('no escape' and 'not feeling safe in my own home'). Arguably, unlike face-to-face contexts, powerlessness is not experienced as a perpetrator's outward expression of power, but more as a victim's perception of powerlessness in escaping the behaviour (Dooley et al. 2009).

Therefore, similar to face-to-face bullying power imbalances appear to be a part of individual experiences of cyberbullying. However, the notion that the online environment may enhance social power (as a result of shared norms) and that the nature of cyberbullying may enhance victim powerlessness, suggests some qualitative differences with face-to-face contexts.

\section{Coping}

Participants employed a range of strategies for coping - including avoidance, confronting, control and revenge. Most participants tended to exhibit an avoidant approach, which concurs with the traditional bullying literature (Ólafsson and Jóhannsdóttir, 2004). However, the virtual nature to the communication may promote more negative coping styles. For example, two participants who displayed avoiding coping reported that they would have coped better with traditional bullying, but the lack of physical co-presence with the bully was perceived to promote the avoiding approach. Perhaps as stated above creating a sense of powerlessness which inhibited effective coping.

On the positive side, electronic media may facilitate rather than impede coping as it may afford more control over the situation by empowering the individual to choose the media for communication. It is questionable whether there is this same level of choice in face-to-face bullying.

\section{Unique Features of Cyberbullying}

So far we have examined similarities between cyberbullying as experienced by this sample and research on face-to-face bullying, but features within the cyber context create a qualitatively different experience. One feature which positions cyberbullying apart from face-to-face bullying is the impact of communication media. The reduction in social cues in online communication appears to inhibit communicating empathic feelings, to impede developing trusting relationships and to create perceived aggressive communication, which over time results in experiences of cyberbullying. This latter finding supports reduced social cues models which suggest that removing social cues can make communication less inhibited (Kiesler et al., 1984; Joinson, 2003). Resultantly, a toxic disinhibition effect emerges where individuals express themselves more openly in an aggressive and abusive manner (Suler, 2004).

However, in contrast, reduced social cues may result in misinterpretation of the communication rather than promote disinhibition. The ambiguous emotional tone in email communication and the sender having less opportunity to correct inaccurate perceptions can lead to more emphasis placed on the negative aspects of the email (Byron, 2008). This 'negativity effect' results in receivers: "likely to inaccurately perceive emails as more intensely negative than intended by the sender" (p.314) and may enhance conflict and escalate to cyberbullying. In face-to-face contexts, misinterpretation is either reduced or speedily corrected.

All participants were aware of the potential advantage offered by the ability to record, and to some extent exert control over cyberbullying behaviour. However, participants also recognised that the perpetrator's cognisance of 
this potential and the openness of some electronic communication tended to promote more indirect/covert bullying behaviours. This paints a complex picture of online aggressive interactions and suggests that the escalatory pattern and choice between indirect and direct aggression is potentially more complex than bullying conducted solely face-to-face. This complex interplay between overt and covert, direct and indirect behaviours conducted both 'behind the screens and behind the scenes' has also been recognised in school context (Spears $e t$ al. 2009).

\section{Practical Implications}

The findings from this study have important management implications. With traditional organisational boundaries being de-emphasised, and cyberbullying occurring across organisational jurisdictions, fulfilling a duty of care to employees is problematic. Two areas of practice seem to be particularly important. Firstly, with increases in distributed working, the development of effective virtual leadership appears to be essential. The skills needed to be an effective virtual leader are somewhat different from those required in more traditional frameworks, with the management of diversity and conflict, and the development of trust requiring increased focus (Cascio and Shurygailo, 2003; Zigurs, 2003). Secondly, the development of business policies providing guidance on acceptable behaviours for employees engaging in online social collaboration seems to be critical to both preventing and addressing incidences of cyberbullying.

\section{Limitations}

The sample is small and purposive, and the participants' use of electronic communication media is diverse and contextualised. However, the principles of IPA are first and foremost idiographic and through the themes reported the intention here is to shed light on specific and shared experiences in what is an emerging area of research. With a current dearth of research on cyberbullying encountered through work, and continued debate on what constitutes cyberbullying, this study helps to develop our understanding of the nature and impact of this phenomenon.

It could be argued that findings have not actually captured the concept of cyberbullying as defined in the research literature, because individuals were not provided with a research definition of cyberbullying on which to base their experiences. Indeed, initial reviewers suggested this to be a limitation of the research. We understand this perspective and how this may result in a limited comparison with traditional workplace bullying. However, our intention was to view participants as masters of their own experiences and to assess their lived experiences in relation to how they perceive cyberbullying. What is important here is not whether we have captured cyberbullying as defined by current academic-led definitions, but that we have captured cyberbullying as conceptualised by individual experiences. There are a number of reasons for this. Firstly, although, the literature is reaching some consensus as to what defines cyberbullying, there is still no universally agreed definition of cyberbullying and the distinction between cyberbullying and cyber-aggression is less clear (Li et al., 2012). Secondly, this 'consensus' is generally driven by school or adolescence-based research and there is currently no reason to assume that cyberbullying in working contexts is conceptually similar to cyberbullying in school contexts. Thirdly, even within traditional workplace bullying research there is a distinction between academic conceptualisations and individual perspectives of the phenomenon (Saunders et al, 2007). Therefore, we feel that due to the embryonic nature of research in this area, the approach adopted here allows us to understand how individuals faced with what they perceive as cyberbullying conceptualise their experiences and how this may help researchers better understand the concept within working contexts. We acknowledge however, that caution should be exercised when making comparisons with academic research on face-to-face workplace bullying.

\section{Conclusions}

Shared experiences of cyberbullying were captured in five broad themes and the complexities associated with managing relationships were central to individuals' subjective experiences. Employee experiences of cyberbullying show similarities to some findings in face-to-face bullying research, however cyberspace provides a new forum for creative bullying behaviours and responses to emerge as well presenting unique challenges both for bully, victim and organisations in managing such relationships. Unique features of online communication, the blurring of work boundaries and the tensions between established and new approaches to managing virtually may escalate conflict to the point where victims perceive being cyberbullied and are left feeling powerless and unable to cope effectively. These features add complexity to the cyberbullying experience and suggest that cyberbullying may be different from face-to-face bullying. 


\section{REFERENCES}

Agervold, M. \& Mikkelsen, E. G. (2004). "Relationships between bullying, psychological work environment and individual stress reactions." Work and Stress, 18 (4): 336-351.

Ashforth, B. (1994). "Petty tyranny in organizations.” Human Relations, 47 (7): 755-770.

Ashkenas, R., Ulrich, D., Jick, T. \& Kerr, S. (1993). The Boundaryless Organization: Breaking the Chains of Organizational Structure. San Francisco: Jossey-Bass Publishers.

Baruch, Y. (2005). "Bullying on the Net: Adverse Behaviour on Email and its Impact." Information and Management, 42 (2): 361-371.

Beran, T. \& Li, Q. (2005). "Cyber-harassment: A study of a new method for an old behavior." Journal of Educational Computing Research, 32 (3): 265-277.

Berkowitz, L. (1989). "The frustration-aggression hypothesis: An examination and reformulation". Psychological Bulletin, 106 (1): 59-73.

Bowling, N.A. \& Beehr, T.A. (2006). "Workplace Harassment from the victim's perspective: A theoretical model and meta-analysis." Journal of Applied Psychology, 91 (5): 998-1012.

Byron, K. (2008). "Carrying too heave a load? The communication and miscommunication of emotion by email." Academy of Management Review, 33 (2): 309-327.

Campbell, M. A. (2005). "Cyber bullying: An old problem in a new guise?" Australian Journal of Guidance and Counselling, 15 (1): 68-76.

Cascio, W. F. \& Shurygailo, S. (2003). "E-Leadership and virtual teams.” Organizational Dynamics, 31 (4): 362-376.

Coyne, I. (2011). 'Workplace Bullying', in C. P. Monks and I. Coyne (Eds.), Bullying in Different Contexts (pp. 157-184). Cambridge: Cambridge University Press.

Coyne, I., Seigne, E. \& Randall, P. (2000). "Predicting workplace victim status from personality." European Journal of Work and Organisational Psychology, 9 (3): 335-350.

Daft, R. L. \& Lengel, R. H. (1986). "Organizational information requirements media richness and structural design." Management Science, 32 (5): 554-571.

Djurkovic, N., McCormack, D. \& Casimir, G. (2004). "The physical and psychological effects of workplace bullying and their relationship to intention to leave: A test of the psychosomatic and disability hypotheses." International Journal of Organizational Theory and Behavior, 7 (4): 469-497.

Dooley, J. J., Pyzalski, J. \& Cross, D. (2009). "Cyberbullying versus face-to-face bullying: a theoretical and conceptual review." Zeitschrift für Psychology/Journal of Psychology, 217 (4): 182-189.

Einarsen, S., Hoel, H., Zapf, D. \& Cooper, C. L. (Eds.), (2010). Bullying and Harassment in the Workplace: Developments in Theory, Practice and Research (2nd ed.). London: CRC Press.

Hinds, P. J. \& Bailey, D. E. (2003). "Out of sight, out of synch: Understanding conflict in distributed teams." Organization Science, 14 (6): 615-632.

Hoel, H., Cooper, C. L. \& Faragher, B. (2001). "The experience of bullying in Great Britain: The impact of organizational status." European Journal of Work and Organizational Psychology, 10 (4): 443-465.

Hoel, H. \& Salin, D. (2003). "Organisational antecedents of workplace bullying" (pp. 210-218). In S. Einarsen, H. Hoel, D. Zapf, \& C. L. Cooper, (Eds.), Bullying and Emotional Abuse in the Workplace: International perspectives in research and practice. London: CRC Press.

Joinson, A. N. (2003). Understanding the psychology of Internet Behaviour. Palgrave New York: MacMillan.

Kiesler, S., Siegel, J. \& McGuire, T. W. (1984). "Social psychological aspects of computer-mediated communication." American Psychologist, 39 (10): 1123-1134.

Kowalski, R. M., Limber, S. P. \& Agatston, P. W. (2008). Cyberbullying: Bullying in the Digital Age. Malden, MA: Blackwell Publishing. 
Lea, M., O'Shea, T., Fung, P. \& Spears, R. (1992). ““Flaming” in computer-mediated communication: Observations, explanations, implications" (pp. 89-112). In M. Lea (Ed.), Contexts of Computer-mediated Communication. New York: Harvester-Wheatshead.

Leymann, H. (1996). "The content and development of mobbing at work." European Journal of Work and Organizational Psychology, 5 (2): 165-184

Li, C., \& Bernoff, J. (2008). Groundswell. Winning in a World Transformed by Social Technologies. Harvard, MA: Harvard Business School Press.

Li, Q. (2006). "Cyberbullying in schools: A research of gender differences." School Psychology International. 27 (2): 157-170.

Li, Q., Cross, D. \& Smith, P. (2012) (Eds.), Cyberbullying in the Global Playground. Research from International Perspectives. Chichester: Wiley-Blackwell.

Lieber, L. D. (2010). "Harassment goes viral—what can HR do to prevent it?" Employee Relations Today, 37 (2): 81-89.

Lutgen-Sandvik, P., Tracy, S. J. \& Alberts, J. K. (2007). "Burned by bullying in the American workplace: Prevalence, perception, degree and impact." Journal of Management Studies, 44 (6): 837-862.

Mannix, E. A., Griffith, T. L. \& Neale, M. A. (2002). "The phenomenology of conflict in distributed work teams" (pp. 213-234). In P. J. Hinds and S. Kiesler (Eds.), Distributed Work, Cambridge, MA: MIT Press.

McAfee, A. (2009), Enterprise 2.0: New Collaborative Tools for Your Organization's Toughest Challenge. Harvard, MA: Harvard Business School Press.

Mishna, F., Saini, M. \& Solomon, S. (2009). "Ongoing and online: Children and youth's perceptions of cyber bullying." Children and Youth Services Review, 31 (12): 1222-1228.

Ólafsson, R. F. \& Jóhannsdóttir, H. L. (2004). "Coping with bullying in the workplace: the effect of gender, age and type of bullying." British Journal of Guidance and Counselling, 32 (3): 319-333.

Patchin, J. \& Hinduja, S. (2006). "Bullies Move beyond the Schoolyard: A Preliminary Look at Cyberbullying." Youth Violence and Juvenile Justice, 4 (2): 148-169.

Poole, M. S. \& DeSanctis, G. (1990). "Understanding the use of group decision support systems: the theory of adaptive structuration" (pp.173-193). In J. Fulk, and C. Steinfield (Eds.), Organizations and Communication Technology. London: Sage Publications.

Postmes, T., Spears, R. \& Lea, M. (1998). "Breaching or building social boundaries." Communication Research, 25 (6): 689-715.

Privitera, C. \& Campbell, M. A. (2009). "Cyber-bullying: The new face of workplace bullying?" CyberPsychology \& Behavior, 12 (4): 395-400.

Raskauskas, J. \& Stoltz, A.D. (2007). "Involvement in traditional and electronic bullying among adolescents." Developmental Psychology, 43 (3): 564-575.

Reicher, S. (1982). "The determination of collective behavior" (pp. 41-83). In H. Tajfel, (Ed.), Social Identity and Intergroup Relations. Cambridge: Cambridge University Press.

Reicher, S., Spears, R. \& Postmes, T. (1995). "A social identity model of deindividuation phenomena”. European Review of Social Psychology, 6 (1): 161-198.

Rivers, I., Chesney, T., \& Coyne, I. (2011). "Cyberbullying” (pp.211-230). In C. P. Monks and I. Coyne (Eds.), Bullying in Different Contexts. Cambridge: Cambridge University Press.

Salin, D. (2003). "Ways of explaining workplace bullying: A review of enabling, motivating and precipitating structures and processes in the work environment." Human Relations, 56 (10): 1213-1232

Saunders, P., Huynh, A., \& Goodman-Delahunty, J. (2007). "Defining workplace bullying behaviour professional lay definitions of workplace bullying". International Journal of Law and Psychiatry, 30 (4-5): 340-354. 
Seigne, E., Coyne, I., Randall, P. \& Parker, J. (2007). "Personality traits of bullies as a contributory factor in workplace bullying: An exploratory study." International Journal of Organizational Theory and Behavior, 10 (1): 118-132.

Siegel, J., Dubrovsky, V., Kiesler, S. \& Mcguire, T. (1986). "Group Processes in Computer-Mediated Communication”. Organizational Behavior and Human Decision Processes, 37: 157-187.

Slonje, R. \& Smith, P. K. (2008). “Cyberbullying: Another main type of bullying?” Scandinavian Journal of Psychology, 49 (2): 147-154.

Smith, J. A. \& Osborn, M. (2003). "Interpretative phenomenological analysis" (pp.51-80). In J. A. Smith (Ed.), Qualitative psychology: A practical guide to research methods. London: Sage Publications, Ltd.

Smith, J. A., Harre, R. \& Van Langenhove, L. (1995). "Idiography and the case study" (pp.59-69). In J. A. Smith, R. Harre and L. Van Langenhove (Eds.), Rethinking Psychology. London: Sage Publications Ltd.

Smith, J. A., Flowers, P. \& Larkin, M. (2009). Interpretative Phenomenological Analysis. Theory, Method and Research. London: Sage Publications Ltd.

Smith, P. K., Mahdavi, J., Carvalho, M., Fisher, S., Russell, S. \& Tippett, N. (2008). "Cyberbullying: Its nature and impact in secondary school pupils." Journal of Child Psychology and Psychiatry, 49 (4): 376-385.

Spears, B., Slee, P., Owens, L. \& Johnson, B. (2009). "Behind the scenes and screens: Insights into the human dimension of covert and cyber bullying." Zeitschrift für Psychology/Journal of Psychology, 217 (4): 189-197.

Sproull, L. \& Kiesler, S. (1986). "Reducing social context cues: electronic mail in organizational communication." Management Science, 32 (11): 1492-1512.

Suler, J. (2004). “The Online Disinhibition Effect”. CyberPsychology \& Behavior, 7 (3): 321-326.

Tajfel, H., \& Turner, J. (1986). "The Social Identity Theory of Intergroup Behavior" (pp.7-24). In S. Worchel and W. G. Austin (Eds.), Psychology of Intergroup Relations. Chicago: Nelson.

Tapscott, D., \& Cook, N. (2008). Enterprise 2.0: How Social Software Will Change the Future of Work. London: Gower Publishing Ltd.

Wallace, P. (2001). The Psychology of the Internet. Cambridge: Cambridge University Press.

Ybarra, M. L. (2004). "Linkages between depressive symptomatology and Internet harassment among young regular Internet users." CyberPsychology \& Behavior, 7 (2): 247-257

Zapf, D. \& Gross, C. (2001). "Conflict escalation and coping with workplace bullying: A replication and extension." European Journal of Work and Organizational Psychology, 10 (4): 497-522.

Zapf, D., \& Einarsen, S. (2003). "Individual Antecedents of Bullying” (pp.165-184). In S. Einarsen, H. Hoel, D. Zapf, and C. L. Cooper (Eds.), Bullying and emotional abuse in the workplace. International perspectives in research and practice. London: CRC Press.

Zigurs, I. (2003). "Leadership in virtual teams: Oxymoron or opportunity?" Organizational Dynamics, 31 (4): $339-351$ 
Appendix 1: Example quotations by themes

\begin{tabular}{|c|c|}
\hline $\begin{array}{l}\text { Superordinate themes } \\
\qquad \text { Subordinate themes }\end{array}$ & Example quotations \\
\hline \multicolumn{2}{|l|}{ Attributions of causality } \\
\hline $\begin{array}{l}\text { Attributions to situational \& } \\
\text { organisational factors }\end{array}$ & $\begin{array}{l}\text { "I actually would not completely blame the individual, because I } \\
\text { think at that point, erm, it was a high pressured situation for a lot of } \\
\text { people in the company, erm, restructuring, erm, budgets being cut, } \\
\text { consolidated, whatever" [John, organisational change] }\end{array}$ \\
\hline Attributions to self & $\begin{array}{l}\text { "She realised that she could say these things to me, and send me } \\
\text { these emails and there was no reaction because it's the type of } \\
\text { person I am." [Alison] }\end{array}$ \\
\hline Attributions to perpetrators & $\begin{array}{l}\text { "staff said she was scary to be with. And a lot of them said she was } \\
\text { a lady that knows what she wants" [Alison] }\end{array}$ \\
\hline \multicolumn{2}{|l|}{ Crossing of Boundaries } \\
\hline $\begin{array}{l}\text { Boundary between work and } \\
\text { personal life }\end{array}$ & $\begin{array}{l}\text { "over the course of the three weeks there were thirty, forty emails } \\
\text { from members of the board and at one point one of them had passed } \\
\text { my email address onto somebody else, she'd come up with an idea } \\
\text { that they wanted to negotiate with me when I came back, and they'd } \\
\text { given them my private email address. So I ended up getting work } \\
\text { based emails whilst I was on holiday, even though I'd expressly said } \\
\text { I wouldn't be checking my emails." [Mark] }\end{array}$ \\
\hline $\begin{array}{l}\text { Boundaries between established } \\
\text { and emerging organisational } \\
\text { structures }\end{array}$ & $\begin{array}{l}\text { "so there was a sense of..., we knew who belonged, and we could } \\
\text { tell who didn't belong, and who wanted to but who didn't want to, } \\
\text { yunno, someone who wanted to have a top down controlling..., } \\
\text { whereas we wanted to have a bottom-up..., yunno, flat } \\
\text { hierarchy."[Tony] }\end{array}$ \\
\hline \multicolumn{2}{|l|}{$\begin{array}{l}\text { Influence of Communication Richness } \\
\text { on Relationship Development }\end{array}$} \\
\hline $\begin{array}{l}\text { Role of Empathy, Socialisation } \\
\text { and Disclosure to Trust } \\
\text { Formation }\end{array}$ & $\begin{array}{l}\text { "Throughout the months, from when it started through to that point } \\
\text { she clearly had no idea of her...., at all. And people, to me.., you } \\
\text { always..., I know at the end of the day there's a job to be done, and } \\
\text { if you are a manager you clearly have to stand in your position and } \\
\text { everything else, but you do see a soft side to people, and at some } \\
\text { stage you see something throughout. Course it was hard because of } \\
\text { the distance so we didn't see each other, we spoke on the phone, } \\
\text { and via email, so to me I'd already got this vision of this women in } \\
\text { my head, and as I say at the point she clearly had no...,I'd seen no } \\
\text { warmth, even when we finished our meetings, even at the very } \\
\text { beginning before any of this started, there was no like social talk or } \\
\text { anything like that. So that's what made me, I think, think she was } \\
\text { such an Iron Lady so to speak." [Alison] }\end{array}$ \\
\hline $\begin{array}{l}\text { Significance of Verbal and Non- } \\
\text { Verbal Cues }\end{array}$ & $\begin{array}{l}\text { "when it's verbal, it's much harder for the person to conceal their } \\
\text { obvious rage, and you can see that anger there, and that sort of } \\
\text { contempt, and the spitting voice, and body language you can see } \\
\text { they're angry, but when it's written that, yunno, it's just whether }\end{array}$ \\
\hline
\end{tabular}




\begin{tabular}{|c|c|}
\hline & $\begin{array}{l}\text { it's..., what... Well you can see this person is really being nasty here } \\
\text { because they're wound up, so there is no question this is an } \\
\text { aggressive attack, whereas on an email you don't actually know, } \\
\text { yunno, I mean, someone could write to you in a way that you feel } \\
\text { hurt by but it could be quite legitimate for them." [Andrew] }\end{array}$ \\
\hline \multicolumn{2}{|l|}{$\begin{array}{l}\text { Influence of Communication } \\
\text { Explicitness and Openness }\end{array}$} \\
\hline $\begin{array}{l}\text { Influence on perpetrator's } \\
\text { bullying behaviours (indirect } \\
\text { versus indirect) and impact on } \\
\text { victim }\end{array}$ & $\begin{array}{l}\text { "the more cryptic it is the less robust your argument is, the evidence } \\
\text { is that you're being bullied, so this is a bit complicated, I'm saying } \\
\text { on the one hand if it's an email there is evidence, but that's..., the } \\
\text { person doing it is aware of that, so, it's a fine balance between them } \\
\text { wanting to bully and control you, but at the same time knowing they } \\
\text { have to cover their tracks and being able to say, it's just being } \\
\text { paranoid and I just mean this, so it all becomes a game between..., a } \\
\text { game of cat and mouse." [Andrew] }\end{array}$ \\
\hline Influence on group dynamics & $\begin{array}{l}\text { "a new breed of people, who that would come along and joined this } \\
\text { community...but there was definitely a sense of us being shepherded, } \\
\text { yunno, in terms of the kind of views that we could, err, express, erm, } \\
\text { and there was a kind of a company line emerging." [John] }\end{array}$ \\
\hline \multicolumn{2}{|l|}{ Strategies for Coping } \\
\hline Avoiding & $\begin{array}{l}\text { "I managed to hold it together, because, she couldn't see me. And I } \\
\text { told her what she wanted to hear, and I was: 'Yeah, I'll do that, and } \\
\text { I'll do that..." [Alison] }\end{array}$ \\
\hline Confronting & $\begin{array}{l}\text { "I'm on holiday, I have the right to be on holiday, to take three } \\
\text { weeks off work, I've booked the time, I'm entitled to the time, I don't } \\
\text { expect a) to receive emails from you on my private account. [...]. I } \\
\text { said that this is now getting to be an untenable situation, and we } \\
\text { need to get to the bottom of it, because I can't carry on like this, I'm } \\
\text { not prepared to carry on like this. And they said are you } \\
\text { threatening us. [...]. So that, it was kind of getting to a point where } \\
\text { the situation was pretty untenable, and then I realised that what } \\
\text { they were doing is setting up situations after that to make things } \\
\text { worse." [Mark] }\end{array}$ \\
\hline Controlling & $\begin{array}{l}\text { "he wanted to phone me, I declined that opp..., that.., erm..., as I } \\
\text { wanted to keep things, yunno, when someone got aggressive at me, I } \\
\text { thought it better to keep things in some form of written format that I } \\
\text { could...., I also chose not to respond after that point to the } \\
\text { individual." [Tony] }\end{array}$ \\
\hline Seeking Revenge & $\begin{array}{l}\text { "It became humorous in that you could drag this person to have a } \\
\text { conversation about something, they didn't want to have a }\end{array}$ \\
\hline
\end{tabular}


conversation about, in an environment they weren't comfortable in, yunno, and not really understanding the conversation that was taking place at times, so, yunno, and because there was a close knit community around that, a lot of people understood what had happened to me, who supported me, and knew this individual, and it became, yunno, it was an in-joke - can you get him to leap at this one, can we get him to leap at that one, can we get him to leap at that one...." [Tony] 